Tropical Journal of Pharmaceutical Research January 2021; 20 (1): 129-134

ISSN: $1596-5996$ (print); 1596-9827 (electronic)

(C) Pharmacotherapy Group, Faculty of Pharmacy, University of Benin, Benin City, 300001 Nigeria.

Original Research Article

http://dx.doi.org/10.4314/tjpr.v20i1.19

\title{
Effect of Hedyotis diffusa Willd extract on gouty arthritis in rats
}

\author{
LanFang Wang1, Fang OuYang ${ }^{2}$, Yan $\mathrm{Ma}^{2}$, Rui Sun ${ }^{2}$, ShiWei $\mathrm{Tan}^{2}$, Liu Xiao ${ }^{2}$ and \\ QuanWei Yang ${ }^{3 *}$ \\ ${ }^{1}$ Department of Pharmacy, Chongqing Orthopedic Hospital of Traditional Chinese Medicine, Chongqing 400100, ${ }^{2}$ Department
} of Rehabilitation Medicine, ${ }^{3}$ Department of Pharmacy, Wuhan No. 1 Hospital, Wuhan 430022, Hubei, China

*For correspondence: Email: yangquanwei17004@163.com; Tel: +86-18571710475

\begin{abstract}
Purpose: To investigate the effect of Hedyotis diffusa Willd extract (HDWE) on gouty arthritis in rats. Method: Monosodium urate (MSU) crystal was injected into the ankle joint of rats to establish a rat model of gouty arthritis. HDWE $(4.8,9.6$ and $19.2 \mathrm{~g} / \mathrm{kg})$ was administered to the rats treated with MSU crystals. The walking behavior of the rats was observed daily, and the gait score was calculated to evaluate the Oswestry disability index of rats. Levels of IL-1 $\beta$ and TNF- $\alpha$ in lavage fluid of articular cavities were measured using enzyme linked immunosorbent assay (ELISA) kits. The synovial tissues of joint of control, model and $19.2 \mathrm{~g} / \mathrm{kg}$ HDWE group rats were obtained and NLRP3 inflammasome was analysed by Western blot.

Results: The results showed that HDWE ameliorated the symptoms of gouty arthritis and gait score in rats significantly $(p<0.05)$. Further pharmacological experiments showed that all doses of HDWE decreased the levels of inflammatory cytokines IL-1 $\beta$ and TNF- $\alpha(p<0.05)$, and inhibited NLRP3, caspase-1, ASC, IL-1 $\beta$ and IL-18 protein expressions of the lavage fluid of articular cavities in MSU crystal-treated rats $(p<0.01)$.

Conclusion: The results indicate that HDWE exhibits a significant effect in ameliorating gouty arthritis via inhibition NLRP3 inflammasome, and thus is a potential new drug choice for the treatment of gouty arthritis.
\end{abstract}

Keywords: Hedyotis diffusa, Caspase, Gouty arthritis, Inflammatory cytokines, NLRP3 inflammasome

\begin{abstract}
This is an Open Access article that uses a fund-ing model which does not charge readers or their institutions for access and distributed under the terms of the Creative Commons Attribution License (http://creativecommons.org/licenses/by/4.0) and the Budapest Open Access Initiative (http://www.budapestopenaccessinitiative.org/read), which permit unrestricted use, distribution, and reproduction in any medium, provided the original work is properly credited.
\end{abstract}

Tropical Journal of Pharmaceutical Research is indexed by Science Citation Index (SciSearch), Scopus, International Pharmaceutical Abstract, Chemical Abstracts, Embase, Index Copernicus, EBSCO, African Index Medicus, JournalSeek, Journal Citation Reports/Science Edition, Directory of Open Access Journals (DOAJ), African Journal Online, Bioline International, Open-J-Gate and Pharmacy Abstracts

\section{INTRODUCTION}

As an inflammatory arthritis, gouty arthritis is caused by monosodium urate (MSU) crystal deposition in and around the joints [1]. Acute symptoms of gouty arthritis include redness, swelling, heat, pain, and even joint functional loss [2]. This process is driven by neutrophil influx into the joint and leads to the attack of acute inflammatory arthritis with severe pain in the affected tissue. Studies have shown that NOD-like receptors containing a PYD3 (NLRP3) inflammasomes play a critical role in MSUinduced IL-1 $\beta$ secretion in macrophages [3]. There are four kinds of inflammasomes, namely NLRP1, NLRP3, NLRC4, and AIM2. The NLRP3 
inflammasomes play an important role in macrophages by cleaving pro-IL-1 $\beta$ into mature IL-1 $\beta$ [4,5]. MSU activates the NLRP3 inflammasome and synergistically interact with apoptosis-associated speck-like protein (ASC) to drive caspase-1 release, subsequently leading to maturation and secretion of pro-inflammatory cytokines IL-1 $\beta$ and activation of nuclear factor$\mathrm{KB}(\mathrm{NF}-\mathrm{KB})$. This process is involved in inflammatory response in the gouty arthritis [6]. It has been found that MSU-induced inflammation and pain responses are significantly reduced in NLRP3-deficient mice [7]. Regretfully, current gout pain management is far from being satisfactory [8]. Hence, safer and more potent drugs are needed for the treatment of gouty arthritis pain.

Nowadays, a number of herbal drugs and their active ingredients attract increased interest in the protection against gouty arthritis [9-12]. Hedyotis diffusa Willd has been used for the treatment of gouty arthritis for many years, and has achieved obvious curative effect in China. This study employed MSU crystals-treated rats to evaluate the effect of HDWE on gouty arthritis in rats.

\section{EXPERIMENTAL}

\section{Reagents and drugs}

Hedyotis diffusa Willd extract (HDWE) was prepared by our lab according to the standard preparation method of traditional Chinese medicine decoction. Enzyme-linked immunosorbent assay (ELISA) kits for IL-1 $\beta$ and tumor necrosis factor-alpha (TNF- $\alpha)$ were obtained from Shenzhen Xin Bo Sheng Biotechnology Co. Ltd. (Shenzhen, China). The antibodies of NLRP3 (No. bs-6655R), caspase-1 P20 (No. bs-10442R), ASC (No. bs-6741R), IL$1 \beta$ (No. bs-0812R) and IL-18 (No. bs-0529R) for rat were purchased from Beijing Bioss Biotechnology Co., Ltd (China). The antibodies of $\beta$-actin were from Wuhan Servicebio Co., Ltd. All other reagents used were standard laboratory reagents of analytical grade and were purchased locally. Monosodium urate (MSU) crystal were prepared by crystallization of a supersaturated solution of uric acid (Aldrich Chemical Company, Inc.) under mildly basic conditions according to the method used in a previous study [3]. The concentration of MSU crystals suspension was $20 \mathrm{mg} / \mathrm{mL}$.

\section{Animals}

Sixty male rats (Sprague-Dawley, 200 - $220 \mathrm{~g}$ ) were purchased from Hubei Experimental Animal Center (Wuhan, China) and were housed for one week to adapt to the environment before being used for experiments. All the animals were maintained on standard laboratory conditions of temperature $23 \pm 2{ }^{\circ} \mathrm{C}$ and a 12-h light/12-h dark cycle with free access to commercial food and pure water for the duration of the study. The rat experiment was approved by the Animal Care and Use Committee of Wuhan No. 1 Hospital (approval ref no. 20190936), and was carried out in compliance with Directive 2010/63/EU on the handling of animals used for scientific purposes [13]. All the procedures were in strict accordance with the PR China legislation on the use and care of laboratory animals.

\section{Establishment of MSU-induced gouty arthritis model and drug administration}

Homogenous suspensions of celecoxib was made with distilled water. Fresh solution was prepared before each experiment. All the rats were randomly divided into six groups of 10 rats each. Group I was injected with PBS and served as a normal (control) group. Group II injected with $100 \mu \mathrm{L}$ MSU crystal suspension served as a model group. Group III comprised of MSU crystals-treated rats were administered with celecoxib (0.019 $\mathrm{g} / \mathrm{kg}$ body weight). Group IV, Group V and Group VI comprised of MSU crystals-treated rats were administered HDWE $(19.2, \quad 9.6$ and $4.8 \mathrm{~g} / \mathrm{kg}$ body weight, respectively). All drug administrations of different group rats lasted for 9 days once daily. At the 7th day of drug administration, rats were anesthetized with $20 \%$ urethane solution, and then MSU crystals suspension $(100 \mu \mathrm{L})$ or PBS $(100 \mu \mathrm{L})$ was injected into the tibiotarsal joint (ankle) of rats.

\section{Assessment of walking behavior and gait score}

The walking behavior of rats was observed every day. According to the Coderre's Method [14], the gait score was calculated to evaluate the Oswestry disability index of rats at 2, 6, 12, 24 and $48 \mathrm{~h}$.

\section{Determination of cytokine levels in the joint of MSU crystals-treated rats}

After the last drug administration, the lavage fluids (including PBS and synovial fluid) were collected. Each lavage fluid of articular cavities was diluted with PBS to the volume of $1 \mathrm{~mL}$. The lavage fluids were centrifuged at $500 \mathrm{~g}$ for $10 \mathrm{~min}$ and supernatants were stored at $-80{ }^{\circ} \mathrm{C}$ before biochemical determinations. Levels of IL-1 $\beta$ and TNF- $\alpha$ in lavage fluid of articular cavities were measured with ELISA kits (according to manufacturer's instructions). 


\section{Western blotting analysis}

Three synoviums of injected ankles after being irrigated with PBS were isolated. About $50 \mathrm{mg}$ of frozen rat articular synovium were homogenized in $1 \mathrm{ml}$ RIPA buffer, and then centrifuged at $10,000 \mathrm{~g}$ for $20 \mathrm{~min}$. Protein concentrations of the supernatants were measured with the Bradford method. The volumes equivalent to 30 mg of proteins were analyzed by $10 \%$ SDSPAGE under non reducing conditions. After electrophoresis, polyacrylamide gels were blotted onto polyvinylidene fluoride membrane. Membranes were washed in Tris-HCl-buffered saline (TBS, $50 \mathrm{mM}, \mathrm{pH}$ 7.5) and incubated in $5 \%$ dried skim milk for $2 \mathrm{~h}$ and washed twice with tans-buffer (without methanol) and incubated with a primary antibodies, including anti-NLRP3 (1:2000), anti-caspase-1 (1:2000), anti-ASC (1:2000), anti-IL-1 $\beta$ (1:2000), anti-IL-18 (1:2000) and anti- $\beta$-actin antibodies. The membranes were washed and incubated with horseradish peroxidase-conjugated secondary antibodies (Wuhan Servicebio Co., Ltd.). The immune complexes were detected using chemiluminescence (ECL) system.

\section{Statistical analysis}

All data are expressed as mean \pm SEM. Statistical analysis was performed using Student's t-test for two groups or a one-way ANOVA for three or more multiple groups (GraphPad Software San Diego, CA, USA). For all results, $p<0.05$ was considered statistically significant.

\section{RESULTS}

HDWE improved the walking behavior and gait score in MSU crystals-treated rats

After the injection of MSU crystals into the ankle joint, joint swelling was observed immediately. Compared with control group $(0 \pm 0.1)$, the Oswestry disability index of model group rats increased significantly at hour $2(2.9 \pm 0.3)$, hour
$6(2.7 \pm 0.7)$, hour $12(2.5 \pm 0.5)$, hour $24(2.4 \pm$ $0.5)$ and hour 48 (2.3 \pm 0.4$)$ (all $p<0.01$,). Celecoxib and HDWE (19.2 $\mathrm{g} / \mathrm{kg})$ ameliorated the Oswestry disability index and walking behavior significantly at different time points respectively $(p<0.01)$ (Table 1$)$.

\section{HDWE attenuated the levels of pro- inflammatory cytokines in MSU crystals- treated rats}

To identify the alterations of pro-inflammatory cytokines after ankle injection of MSU crystals suspension, we determined the levels of proinflammatory cytokines in the lavage fluid of articular cavities collected at $24 \mathrm{~h}$ later of the last drug administration. Compared with control group, IL-1 $\beta$ and TNF- $\alpha$ levels of the lavage fluid of articular cavities in MSU crystals-treated rats were increased significantly $(P<0.01)$. Celecoxib and HDWE $(19.2 \mathrm{~g} / \mathrm{kg})$ both ameliorated them significantly $(P<0.01)$.

\section{HDWE suppressed caspase-1 activation and IL-1 $\beta$ and IL-18 secretion}

In order to understand the effect of HDWE on joint, the effect of HDWE on the NLRP3 inflammasome protein expression was investigated.

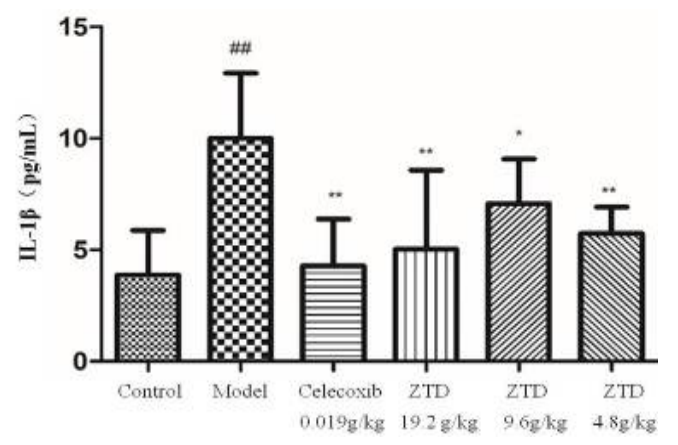

Figure 1: Effect of HDWE on IL-1 $\beta$ level in the lavage fluid of articular cavities in MSU crystals-treated rats

Table 1: Effect of HDWE on gait score in gouty arthritis rats

\begin{tabular}{|c|c|c|c|c|c|c|}
\hline \multirow[t]{2}{*}{ Group } & \multirow{2}{*}{$\begin{array}{c}\text { Dose } \\
\text { (g/kg) }\end{array}$} & \multicolumn{5}{|c|}{ Oswestry disability index } \\
\hline & & $2 \mathrm{~h}$ & 6h & $12 \mathrm{~h}$ & $24 h$ & 48h \\
\hline Control & - & $0.0 \pm 0.1$ & $0.0 \pm 0.1$ & $0.0 \pm 0.1$ & $0.0 \pm 0.1$ & $0.0 \pm 0.1$ \\
\hline Model & - & $2.9 \pm 0.3^{\# \#}$ & $2.7 \pm 0.7^{\# \#}$ & $2.5 \pm 0.5^{\# \#}$ & $2.4 \pm 0.5^{\# \#}$ & $2.3 \pm 0.4^{\# \#}$ \\
\hline Celecoxib & 0.019 & $2.4 \pm 0.6^{*}$ & $1.8 \pm 0.4^{* \pi}$ & $1.4 \pm 0.4^{* *}$ & $1.2 \pm 0.3^{* \pi}$ & $1.0 \pm 0.2^{* *}$ \\
\hline HDWE-H & 19.200 & $2.5 \pm 0.6^{\pi}$ & $2.0 \pm 0.5^{\star \pi}$ & $1.7 \pm 0.4^{\pi \pi}$ & $1.1 \pm 0.3^{\pi \pi}$ & $0.9 \pm 0.3^{\pi \pi}$ \\
\hline HDWE-M & 9.600 & $2.6 \pm 0.7$ & $2.3 \pm 0.5^{x}$ & $2.0 \pm 0.5^{x}$ & $1.9 \pm 0.4^{\pi}$ & $1.6 \pm 0.4^{\pi x}$ \\
\hline HDWE-L & 4.800 & $2.8 \pm 0.4$ & $2.6 \pm 0.6$ & $2.2 \pm 0.6$ & $2.0 \pm 0.5^{*}$ & $1.9 \pm 0.4^{*}$ \\
\hline
\end{tabular}

Compared with control group, ${ }^{\#} p<0.05,{ }^{\# \#} p<0.01$; compared with model group, $p<0.05, " p<0.01$. HDWE-H: high dose of HDWE, HDWE-M: middle dose of HDWE, HDWE-L: low dose of HDWE 


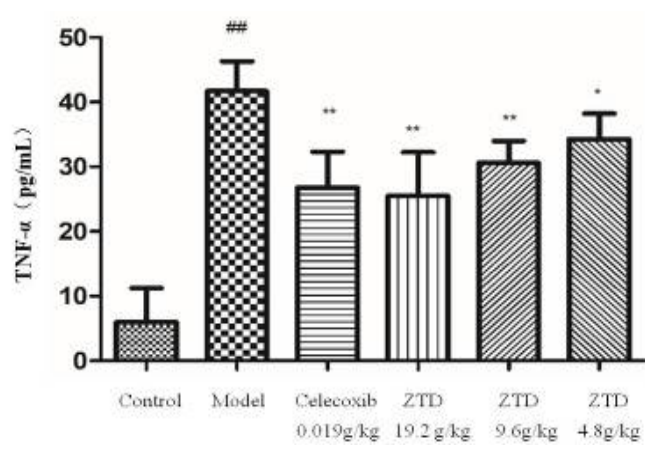

Figure 2: Effect of HDWE on TNF-a level in the lavage fluid of articular cavities in MSU crystalstreated rats
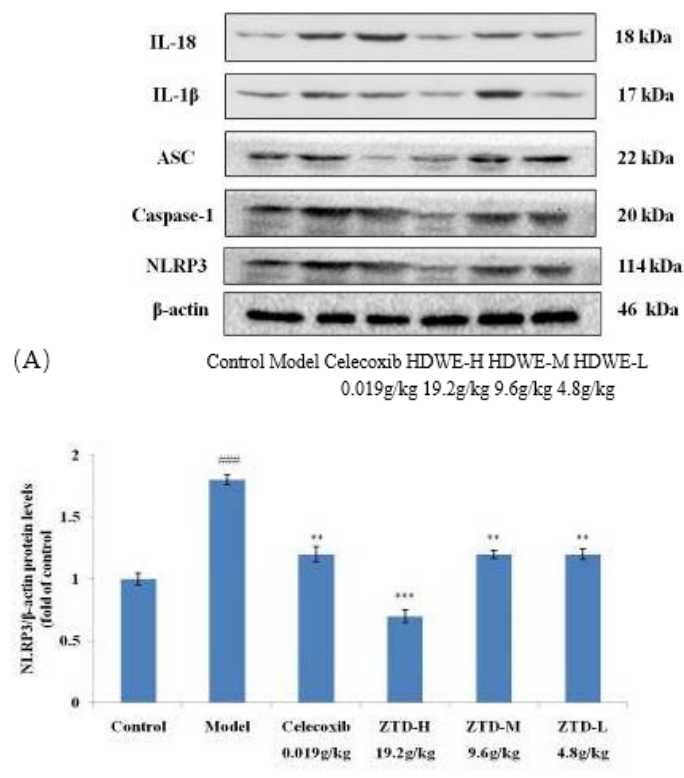

(B) NLRP3 protein

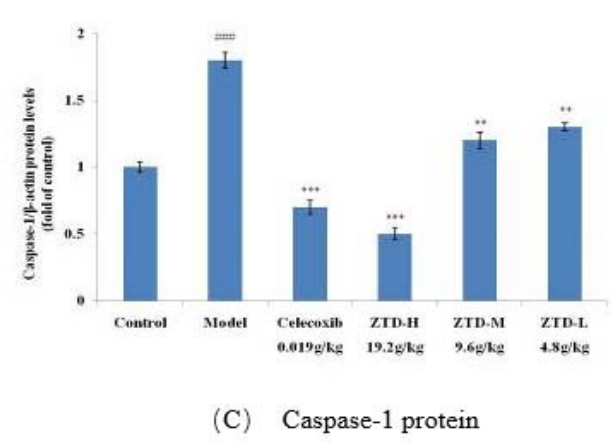

Figure 3: $\operatorname{HDWE}(4.8,9.6$ and $19.2 \mathrm{~g} / \mathrm{kg})$ and celecoxib decreased the expressions of inflammationassociated proteins in the synovium of MSU crystalstreated rats. A - C: Protein expressions of control, NLRP3 and caspase-1 P20, were determined by western blotting and the bar chart indicated the relative protein. expression. ${ }_{* \star * \#}^{\# * *} P<0.001$ vs. control rats; $p<0.05, \quad p<0.01,{ }^{* * *} p<0.001$ vs. MSU crystals-treated rats
Compared to the control group, the protein expressions of NLRP3, caspase-1, ASC, IL-1 $\beta$ and IL-18 proteins were all up-regulated in the MSU-treated group $(p<0.01)$, suggesting that the inflammatory status might be involved in the articulation dysfunction. As shown in Figure 3 and Figure 4, the results showed that HDWE $(4.8,9.6$ and $19.2 \mathrm{~g} / \mathrm{kg})$ and celebrex decreased NLRP3, caspase-1, ASC, IL-1 $\beta$ and IL-18 protein expression in rats respectively (all $p<0.01$ ).

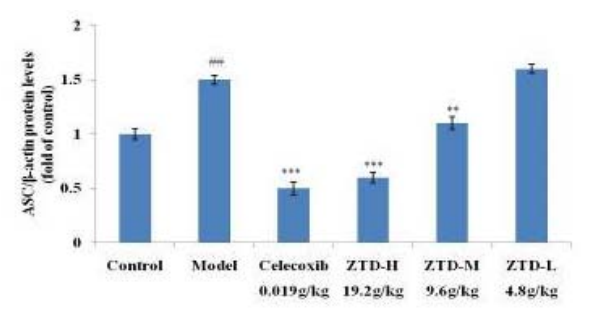

(A) ASC protein

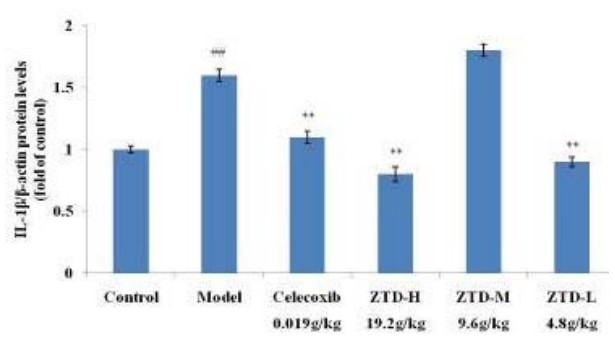

(B) IL-1 $\beta$ protein

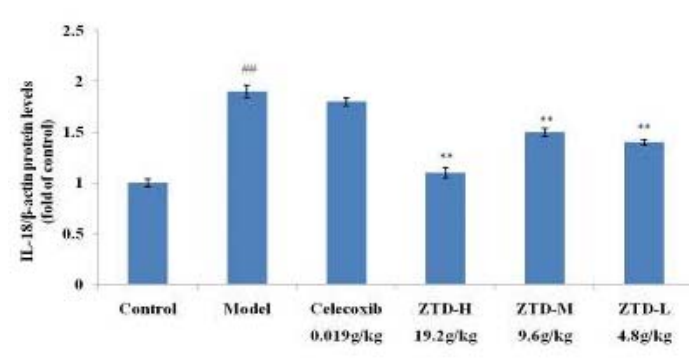

(C) $\mathrm{IL}-18$ protein

Figure 4: HDWE (4.8, 9.6 and $19.2 \mathrm{~g} / \mathrm{kg})$ and celecoxib decreased the expressions of inflammationassociated proteins in the synovium of MSU crystalstreated rats. A - C: Protein expressions of ASC, IL-1 $\beta$ and IL-18, as evaluated by western blotting. $P<$ 0.001 vs. control rats; ${ }^{*} p<0.05,{ }^{* *} p<0.01,{ }^{* * *} p<0.001$ vs. MSU crystals-treated rats

\section{DISCUSSION}

Gout is caused mainly by the accumulation of MSU crystals in the joints, and it is characterized by IL-1 $\beta$-driven acute inflammation which is associated with the infiltration of monocytemediated neutrophils in the joints [15]. Evidence shows that crystals from the synovial fluid of 
patient with gout are composed of MSU crystals [16]. MSU crystal is widely recognized as a danger signal to promote an acute inflammation in the joint cavity, and MSU crystal is most frequently employed to develop an animal model of gouty arthritis $[17,18]$. Neutrophil recruitment and activation in both joint fluid and synovial membrane is a hallmark the acute inflammatory response to MSU crystals in acute gouty arthritis [19]. In the present study, MSU crystals-induced joint swelling and thermal hyperalgesia elevating in the present study were obviously observed in rats, suggesting the acute inflammation in the joint cavity. HDWE treatment attenuate the pain threshold value and the joint swelling degree in MSU crystals-treated rats significantly.

The objectives for gout treatment include managing the symptoms of acute attack and preventing further attacks by reducing uric acid levels in the blood. The most commonly used therapies for acute gout in general practice nonsteroidal anti-inflammatory drugs (NSAIDs), colchicine, celecoxib and corticosteroids. Although these drugs have certain therapeutic effects, they present serious side effects, such as liver and kidney damage and severe gastrointestinal reactions [20,21]. Moreover, the treatment of gout is often a long-term process. Therefore, it is urgent to search for more safer drugs.

The NLRP3 inflammasome is a cytosolic protein complex composed of NLRP3, ASC, and caspase-1, and it is assembled in response to both microbial infection and endogenous "danger signal" [22]. Activation of NLRP3 inflammasome promotes the maturation and release of several pro-inflammatory cytokines, such as interleukin$1 \beta(I L-1 \beta)$ and IL-18, so it plays critical roles in the initiation of inflammation and the development of immune responses [23-24]. Among several of the inflammasomes, NLRP3 inflammasome is relatively well studied and its activation is linked to age related metabolic diseases and auto-inflammatory diseases [2526]. Therefore, much attentions have been given to find active constituents that can act as specific NLRP3 inflammasome inhibitor [27].

In the present study, differential gene signal network diagram of gene chip analysis revealed that caspase-1, IL-1 $\beta$ and IL-18 genes occupied the core position in the signal network, which suggested NLRP3 inflammasome participated in the pathogenetic process of gouty arthritis. Moreover, we found that HDWE inhibited NLRP3 inflammasome activation, and MSU induced IL$1 \beta$ and IL-18 production and neutrophil infiltration in vivo, suggesting that HDWE ameliorated the gouty arthritis induced by MSU crystals through inhibiting NLRP3 inflammasome.

\section{CONCLUSION}

These findings indicate that HDWE inhibited gouty arthritis through reducing swelling and pain and blocking anti-inflammatory pathway, and it provide new drug choice for the treatment of gouty arthritis in future.

\section{DECLARATIONS}

\section{Conflict of interest}

No conflict of interest is associated with this work.

\section{Contribution of authors}

We declare that this work was done by the authors named in this article and all liabilities pertaining to claims relating to the content of this article will be borne by the authors. LanFang Wang and Fang OuYang performed the experiment. Yan Ma wrote the manuscript. Rui Sun and ShiWei Tan wrote the proposal and designed the manuscript. Liu Xiao conducted data analysis. QuanWei Yang modified the manuscript. LanFang Wang and Fang OuYang contributed equally to this work, and they are cofirst authors. Liu Xiao and QuanWei Yang are cocorresponding authors.

\section{Open Access}

This is an Open Access article that uses a funding model which does not charge readers or their institutions for access and distributed under the terms of the Creative Commons Attribution License (http://creativecommons.org/licenses/by/ 4.0) and the Budapest Open Access Initiative (http://www.budapestopenaccessinitiative.org/rea d), which permit unrestricted use, distribution, and reproduction in any medium, provided the original work is properly credited.

\section{REFERENCES}

1. Busso N, So A. Mechanisms of inflammation in gout. Arthritis Res Ther. 2010; 12: 206-14.

2. Dalbeth N, Merriman TR, Stamp LK. Gout. Lancet. 2016; 388: 2039-52.

3. Martinon F, Pétrilli V, Mayor A, Tardivel A, Tschopp J. Gout-associated uric acid crystals activate the NALP3 inflammasome. Nature. 2006; 440: 237-41.

4. Walsh JG, Muruve DA, C P. Inflammasomes in the CNS. Nat Rev Neurosci. 2014; 15: 84-97.

Trop J Pharm Res, January 2021; 20(1): 133 
5. Latz E, Xiao TS, Stutz A. Activation and regulation of the inflammasomes. Nat Rev Immunol. 2013; 13: 397-411.

6. Qing YF, Zhang QB, Zhou JG, Jiang L. Changes in tolllike receptor (TLR) 4-NFKB-IL1 $\beta$ signaling in male gout patients might be involved in the pathogenesis of primary gouty arthritis. Rheumatol. Int. 2013; 34: 213220.

7. Amaral FA, Costa VV, Tavares LD, Sachs D, Coelho FM, Fagundes CT. NLRP3 inflammasome-mediated neutrophil recruitment and hypernociception depend on leukotriene B4 in a murine model of gout. Arthritis Rheum., 2012; 64: 474-84.

8. Rees F, Hui M, Doherty M. Optimizing current treatment of gout. Nat Rev Rheumatol. 2014; 10: 271-83.

9. Liu HJ, Pan $X X$, Liu BQ. Grape seed-derived procyanidins alleviate gout pain via NLRP3 inflammasome suppression. J Neuroinflammation., 2017; 14: 74-75.

10. Lee YM, Shon EJ, Kim OS. Effects of Mollugo pentaphylla extract on monosodium urate crystalinduced gouty arthritis in mice. BMC Complement Altern Med. 2017; 17: 447-448.

11. Han Wei, Chao Hu, Jinbo Xie. Doliroside A attenuates monosodium urate crystals-induced inflammation by targeting NLRP3 inflammasome. Eur J Pharmacol. 2014; 740: 321-8.

12. Kim YK, Koppula S, Shim DW. Inhibitory Effect and Mechanism of Arctium lappa Extract on NLRP3 Inflammasome Activation. Evid Based Complement Alternat Med. 2018; 2018: 6346734.

13. Coderre TJ, Wall $P D$. Ankle joint urate arthritis in rats provides a useful tool for the evaluation of analgesic and anti-arthritic agents. Pharmacol Biochem Behav., 1988; 29: 461-6.

14. European Commission [homepage on the internet]. Directive 2010/63/EU on the protection of animals used for scientific purposes [cited 2013 Jan 16]. Available from: http://ec.europa.eu/environment/chemicals/lab _animals/legislation_en.htm.
15. Malawista SE, Duff GW, Atkins E, Cheung HS, McCarty DJ. Crystal-induced endogenous pyrogen production. A further look at gouty inflammation. Arthritis Rheumatol. 1985; 28: 1039-1046.

16. Nuki G., Simkin PA. A concise history of gout and hyperuricemia and their treatment. Arthritis Res. Ther. 2006; 8 (suppl 1): S1.

17. Lee HS, Lee CH, Tsai HC, Salter DM. Inhibition of cyclooxygenase 2 expression by diallyl sulfide on joint inflammation induced by urate crystal and IL-1beta." Osteoarthr. Cartil. 2009; 17: 91-99.

18. Martinon F, Mayor A, Tschopp J. The inflammasomes; guardians of the body. Annu. Rev. Immunol. 2009; 27: 229-265.

19. So A. How to regulate neutrophils in gout. Arthritis Res. Ther. 2013; 15, 118.

20. Rees F, Hui M, Doherty M. Optimizing current treatment of gout. Nat Rev Rheumatol. 2014; 10, 271-83.

21. Khanna PP, Gladue HS, Singh MK, FitzGerald JD, Bae S, Prakash S. Treatment of acute gout: a systematic review. Semin Arthritis Rheum. 2014; 44: 31-8.

22. Davis BK, Wen H, Ting JP. The inflammasome NLRs in immunity, inflammation, and associated diseases. Annu. Rev. Immunol. 2011; 29: 707-735.

23. Lamkanfi M, Dixit VM. Inflammasomes and their roles in health and disease. Annu. Rev. Cell Dev. Biol. 2012; 28 : 137-161.

24. Schroder K, Tschopp J. The inflammasomes. Cell 2010; 140: 821-832.

25. Broz P, Dixit VM. Inflammasomes: Mechanism of assembly, regulation and signaling. Nature Reviews Immunology 2016; 16: 407-420.

26. Guo H, Callaway JB, Ting JPY. Inflammasomes: mechanism of action, role in disease, and therapeutics. Nature Medicine 2015; 21: 677-687.

27. Tozser J, Benko S. Natural Compounds as Regulators of NLRP3 Inflammasome-mediated IL-1 $\beta$ Production. Mediators of Inflammation 2016; 2016: 1-16. 